\title{
The Solution of the Heat Conduction Equation in 3D Anisotropic Environment and Possibilities of its Improvement
}

\section{Siltumvadīšanas uzdevuma risinājums anizotropā 3D vidē un tā pilnveidošanas iespējas}

\author{
Maksims Žigunovs ${ }^{1}$, Ilmārs Iltinšš ${ }^{2}$, Michael A. Radin ${ }^{3}$ \\ ${ }^{1,2}$ Rìgas Tehniskà universitāte, Latvija \\ ${ }^{3}$ Ročestera Tehnologiju institūts, ASV
}

\begin{abstract}
Kopsavilkums - Šajā rakstā ir parādīta siltumvadīšanas uzdevuma risinājuma izveide, kas nodrošina paralēlo datu apstrādi, un dots risinājuma uzlabojums, kas samazina aprēkina laiku. Tiek apskatīts, kā dabūtas risinājuma formulas, un tiek aprakstītas datu paralēlās apstrādes iespējas. Galvenais mērkis ir samazināt siltumvadī̌sanas uzdevuma risinājuma laiku, paralelizējot aprēḳinu procesu un sadalot to starp vairākiem datoriem. Galvenais algoritmiskais panākums no padarītā darba ir siltumvadīšanas uzdevuma pārveidošana par aizklātu diferenču shēmu ar trīs diagonālu matricu. Vienādojumu sistēmas ar šāda veida matricu ir iespējams rēḳināt, izmantojot Tomasa algoritmu, kurš ir ievērojami efektīvāks par citiem sistēmu risināšanas paṇēmieniem.
\end{abstract}

Atslēgas vārdi - Paātrinājums, paralēlās datu apstrādes tehnoloğijas lietojums, robežnosacījumi, siltuma pārnese.

\section{IEVADS}

Mūsdienās resursu, laika, naudas utt. ekonomēšanai arvien vairāk un arvien pamatotākā līmen̄̄ tiek lietoti algoritmi/datorprogrammas, kas palīdz veikt prognozi par dažādām ietekmēm uz objektiem. Viena no šādām ietekmēm ir temperatūras ietekme uz objektu un temperatūras iekšējā izplatī̌sanās objekta ietvaros. Mūsdienās pastāv dažādas metodes, kas l̦auj veikt temperatūras izplatīšanās aprēķinus. Šāda veida metožu piemēri ir sastopamie COMSOL (datorprogramma) tipa risinājumos.

Mūsdienās strauji attīstās paralēlo aprēḳinu tehnolog̣ijas, kuras l̦auj paralēli (vienlaicīgi) izpildīt vairākas darbietilpīgas komandas.

Tehnoloǵiskā zin̄ā ir pieejamas lielas skaiț̣ošanas jaudas, kas ir saistîtas gan ar secīgiem, gan paralēliem aprēḳiniem. Moderno CPU (centrālais procesors) frekvences sasniedz $4 \mathrm{GHz}$, GPU (grafiskais procesors) kartēm grafisko procesoru skaits sasniedz 1000 vienības vienā kartē, un katra procesora frekvence sasniedz $1 \mathrm{GHz}$. Tas nozīmē, ka ir iespējams izveidot datorsistēmu, kas ir paredzēta nestacionāru fizikālu parādību modelēšanai trīsdimensiju telpā.
Aktuāli ir spēt prognozēt temperatūras sadalījumu būvēs un tehnologiskos objektos atkarībā no mainīgiem sākuma noteikumiem un ārējiem faktoriem.

To ir iespējams izdarīt, apvienojot diferenču shēmu izstrādi nestacionāriem siltuma vadī̌sanas uzdevumiem anizotropā 3D vidē un paralēlo aprēkininu tehnologijas.

Šajā publikācijā ir aprakstīta mūsu izstrādātā metode diferenču shēmu realizācijā paralēlo aprēḳinu tehnologijāās nestacionāriem siltuma vadīšanas uzdevumiem anizotropā $3 \mathrm{D}$ vidē.

Ieguvums un lietojums šim darbam:

1) diferenču shēmu realizācija ir tiešā veidā saistīta ar paralēlo aprēkinu tehnologíiju;

2) tiek veidota monotona, konservatīva diferenču shēma;

3) tiek nodrošināta iespēja aprēkininos izmantot materiālu un telpisko objektu reālās siltumfizikālās īpašības;

4) tiek iegūti siltuma izplatîšanās $3 \mathrm{D}$ un $2 \mathrm{D}$ (viena plakne no 3D) skati;

5) lietojot paralēlo aprēḳinu tehnologijas, tiks paātrināti aprēkini.

6) lietojot darba rezultātus, būs iespējams ēku un tehnoloǵisko objektu projektētājiem veikt siltuma izplatī̌sanās aprēķinus un secināt, kādi materiāli jāizmanto, lai sasniegtu nepieciešamo siltuma pārnesi.

\section{MATEMĀTISKĀ MODEḶA IZSTRĀDE}

Siltumvadīšanas vienādojums anizotropā 3D apgabalā [1]:

$$
\begin{aligned}
& \frac{Q_{p}}{n R_{T}}=\frac{\partial T}{\partial t}+\frac{v_{x}}{R_{T}} \frac{\partial T}{\partial x}+\frac{v_{y}}{R_{T}} \frac{\partial T}{\partial y}+\frac{v_{z}}{R_{T}} \frac{\partial T}{\partial z} \\
& -\frac{1}{R_{T}} \frac{\partial}{\partial x}\left(\Lambda_{x x} \frac{\partial T}{\partial x}+\Lambda_{x y} \frac{\partial T}{\partial y}+\Lambda_{x z} \frac{\partial T}{\partial z}\right) \\
& -\frac{1}{R_{T}} \frac{\partial}{\partial y}\left(\Lambda_{y x} \frac{\partial T}{\partial x}+\Lambda_{y y} \frac{\partial T}{\partial y}+\Lambda_{y z} \frac{\partial T}{\partial z}\right) \\
& -\frac{1}{R_{T}} \frac{\partial}{\partial x}\left(\Lambda_{z x} \frac{\partial T}{\partial x}+\Lambda_{z y} \frac{\partial T}{\partial y}+\Lambda_{z z} \frac{\partial T}{\partial z}\right), t>0
\end{aligned}
$$


Darbā tiek izmantoti trīs veida robežu nosacījumi.

Galvenā problēma diferenču shēmas realizācijā ir saistīta ar siltuma pārneses tenzoru.

Termodispersijas tenzors tiek pārrakstīts eksponenciālā veidā, saglabājot sasaisti starp koordinātu asīm. Tas padarīja risinājumu l’oti jūtīgu attiecībā pret ieejas datu izmaiṇām un sākuma nosacījumiem.

Siltuma izplatīšanās diferenču shēma 3D gadījumam tiek izveidota, vispirms vienādojumu (1) pārrakstot:

$$
\begin{aligned}
& \frac{\partial T}{\partial t}+V_{x} \frac{\partial T}{\partial x}+V_{y} \frac{\partial T}{\partial y}+V_{z} \frac{\partial T}{\partial z}=\frac{1}{R_{T}} \frac{\partial}{\partial x}\left(\Lambda_{x x} \frac{\partial T}{\partial x}+\Lambda_{x y} \frac{\partial T}{\partial y}+\right. \\
& \left.+\Lambda_{x z} \frac{\partial T}{\partial z}\right)+\frac{1}{R_{T}} \frac{\partial}{\partial y}\left(\Lambda_{y x} \frac{\partial T}{\partial x}+\Lambda_{y y} \frac{\partial T}{\partial y}+\Lambda_{y z} \frac{\partial T}{\partial z}\right)+ \\
& +\frac{1}{R_{T}} \frac{\partial}{\partial x}\left(\Lambda_{z x} \frac{\partial T}{\partial x}+\Lambda_{z y} \frac{\partial T}{\partial y}+\Lambda_{z z} \frac{\partial T}{\partial z}\right),
\end{aligned}
$$

kur $T$ - temperatūra; $t$ - laiks; $x, y$ un $z$ ir telpiskās koordinātas; $V_{x}, V_{y}, V_{z}$ - siltuma avotu elementu masas pārneses ātrums attiecīgi $x, y$ un $z$ virzienā; $R_{T}$ - siltuma saglabāšanās faktors; $\Lambda_{12}$ - siltuma vadīšanas tenzors, kur 1 ir aprēķināmais virziens un 2 ir apakš virziens virzienā 1 .

Diskretizējot vienādojumu (2), tiek izveidota diferenču shēma temperatūras aprēkināšanai laika momentā $l+1$, zinot temperatūras sadalījumu laika momentā $l$ :

$$
\begin{aligned}
& \frac{T_{i j k}^{l+1}-T_{i j k}^{l}}{\tau}=\frac{1}{R_{T}} \frac{\partial}{\partial x}\left(\left(I_{x}\right)_{i+\frac{1}{2} j k}-\left(I_{x}\right)_{i-\frac{1}{2} j k}\right)_{x=x^{*}, y=y^{*}, z=z^{*}}+ \\
& +\frac{1}{R_{T}} \frac{\partial}{\partial y}\left(\left(I_{y}\right)_{i j+\frac{1}{2} k}-\left(I_{y}\right)_{i j-\frac{1}{2} k}\right)_{x=x^{*}, y=y^{*}, z=z^{*}}+ \\
& +\frac{1}{R_{T}} \frac{\partial}{h_{z}^{*}}\left(\left(I_{z}\right)_{i j k+\frac{1}{2}}-\left(I_{z}\right)_{i j k-\frac{1}{2}}\right)_{x=x^{*}, y=y^{*}, z=z^{*}}+\frac{Q T_{i j k}}{n R_{T}},
\end{aligned}
$$

kur $\tau$-laika solis; $l, \quad l+1$ - iterāciju numuri; $i$-diskrētā pozīcija pa $x ; j$-diskrētā pozīcija pa $y ; k$-diskrētā pozīcija pa $z ; Q$ - temperatūras pieaugums esošajā laika solī punktā $(i ; j$; k) [2]; $T_{i j k}$ - temperatūra esošajā laika solī punktā $(i ; j ; k) ; n-$ materiāla porozitātes koeficients; $x^{*}=\left(x_{i}-x_{i-1}\right) / 2 ; y^{*}=\left(y_{j}-\right.$ $\left.y_{j-1}\right) / 2 ; z^{*}=\left(z_{k}-z_{k-1}\right) / 2$.

Vidējās siltuma plūsmas $x, y$ un $z$ asu virzienā tiek izteiktas šādi:

$$
\begin{aligned}
& \left(I_{x}\right)_{i+\frac{1}{2} j k}=\Lambda_{x x} \frac{\exp \left(\rho_{i+\frac{1}{2} j k}\right) T_{i+1 j k}-T_{i j k}}{\frac{1}{\rho_{i+\frac{1}{2} j k}}\left(\exp \left(\rho_{i+\frac{1}{2} j k} h_{x}\right)-1\right)} ; \\
& \left(I_{x}\right)_{i-\frac{1}{2} j k}=\Lambda_{x x} \frac{\exp \left(\rho_{i-\frac{1}{2} j k}\right) T_{i j k}-T_{i-1 j k}}{\frac{1}{\rho_{i-\frac{1}{2} j k}}\left(\exp \left(\rho_{i-\frac{1}{2} j k} h_{x}\right)-1\right)} ;
\end{aligned}
$$

$$
\begin{aligned}
& \left(I_{y}\right)_{i j+\frac{1}{2} k}=\Lambda_{y y} \frac{\exp \left(\rho_{i j+\frac{1}{2} k}\right) T_{i j+1 k}-T_{i j k}}{\frac{1}{\rho_{i j+\frac{1}{2} k}}\left(\exp \left(\rho_{i j+\frac{1}{2} k} h_{y}\right)-1\right)} \\
& \left(I_{y}\right)_{i j-\frac{1}{2} k}=\Lambda_{y y} \frac{\exp \left(\rho_{i j-\frac{1}{2} k}\right) T_{i j k}-T_{i j-1 k}}{\frac{1}{\rho_{i j-\frac{1}{2} k}}\left(\exp \left(\rho_{i j-\frac{1}{2} k} h_{y}\right)-1\right)} ; \\
& \left(I_{z}\right)_{i j k+\frac{1}{2}}=\Lambda_{z z} \frac{\exp \left(\rho_{i j k+\frac{1}{2}}\right) T_{i j k+1}-T_{i j k}}{\frac{1}{\rho_{i j k+\frac{1}{2}}}\left(\exp \left(\rho_{i j k+\frac{1}{2}} h_{z}\right)-1\right)} ; \\
& \left(I_{z}\right)_{i j k-\frac{1}{2}}=\Lambda_{z z} \frac{\exp \left(\rho_{i j k-\frac{1}{2}}\right) T_{i j k}-T_{i j k-1}}{\frac{1}{\rho_{i j k-\frac{1}{2}}}\left(\exp \left(\rho_{i j k-\frac{1}{2}} h_{z}\right)-1\right)} ; \\
& \rho_{i+\frac{1}{2} j k}=\frac{1}{T_{i+1 j k} \Lambda_{x x}}\left(\Lambda_{x y} \frac{T_{i j+1 k}-T_{i j k}}{h_{y}}+\Lambda_{x z} \frac{T_{i j k+1}-T_{i j k}}{h_{z}}-V_{x} T_{i+\frac{1}{2} j k}\right) \\
& \rho_{i-\frac{1}{2} j k}=\frac{1}{T_{i-1 j k} \Lambda_{x x}}\left(\Lambda_{x y} \frac{T_{i j k}-T_{i j-1 k}}{h_{y}}+\Lambda_{x z} \frac{T_{i j k}-T_{i j k-1}}{h_{z}}-V_{x} T_{i-\frac{1}{2} j k}\right) \\
& \rho_{i j+\frac{1}{2} k}=\frac{1}{T_{i j+1 k} \Lambda_{y y}}\left(\Lambda_{y x} \frac{T_{i+1 j k}-T_{i j k}}{h_{x}}+\Lambda_{y z} \frac{T_{i j k+1}-T_{i j k}}{h_{z}}-V_{y} T_{i j+\frac{1}{2} k}\right) \\
& \rho_{i j-\frac{1}{2} k}=\frac{1}{T_{i j-1 k} \Lambda_{y y}}\left(\Lambda_{y x} \frac{T_{i j k}-T_{i-1 j k}}{h_{x}}+\Lambda_{y z} \frac{T_{i j k}-T_{i j k-1}}{h_{z}}-V_{y} T_{i j-\frac{1}{2} k}\right) \text {; } \\
& \rho_{i j k+\frac{1}{2}}=\frac{1}{T_{i j k+1} \Lambda_{z z}}\left(\Lambda_{z x} \frac{T_{i+1 j k}-T_{i j k}}{h_{x}}+\Lambda_{z y} \frac{T_{i j+1 k}-T_{i j k}}{h_{y}}-V_{z} T_{i j k+\frac{1}{2}}\right) \text {; } \\
& \rho_{i j k-\frac{1}{2}}=\frac{1}{T_{i j k-1} \Lambda_{z z}}\left(\Lambda_{z x} \frac{T_{i j k}-T_{i-1 j k}}{h_{x}}+\Lambda_{z y} \frac{T_{i j k}-T_{i j-1 k}}{h_{y}}-V_{z} T_{i j k-\frac{1}{2}}\right) .
\end{aligned}
$$

$\left(I_{x}\right)_{i+1 / 2 j k}$ tiek rēḳināts šādā veidā (līdz̄ịi tiek rēḳināti citu virzienu koeficienti):

$$
\begin{aligned}
& \left(I_{x}\right)_{i+\frac{1}{2} j k} \frac{1}{\Lambda_{x x}} \int_{x_{i}}^{x_{i+1}} \exp \left(\int_{x_{0}}^{x} \frac{\Lambda_{x y} \frac{\partial T}{\partial y}+\Lambda_{x z} \frac{\partial T}{\partial z}-V_{x} T}{T \Lambda_{x x}} \mathrm{~d} x\right) \mathrm{d} x \\
& =\phi_{i+1 j k}-\phi_{i j k} ; \\
& \left(I_{x}\right)_{i+\frac{1}{2} j k}=\frac{\phi_{i+1 j k}-\phi_{i j k}}{\frac{1}{\Lambda_{x x}} \int_{x_{i}}^{x_{i+1}} \exp \left(\int_{x_{0}}^{x} \frac{\Lambda_{x y} \frac{\partial T}{\partial y}+\Lambda_{x z} \frac{\partial T}{\partial z}-V_{x} T}{T \Lambda_{x x}} \mathrm{~d} x\right) \mathrm{d} x} ;
\end{aligned}
$$




$$
\begin{gathered}
\left(I_{x}\right)_{i+\frac{1}{2} j k}=\frac{T_{i+1 j k} \exp \left(\int_{x_{0}}^{x_{i-1}} \frac{\Lambda_{x y} \frac{\partial T}{\partial y}+\Lambda_{x z} \frac{\partial T}{\partial z}-V_{x} T}{T \Lambda_{x x}} \mathrm{~d} x\right)-T_{i j k}}{\frac{1}{\Lambda_{x x}} \int_{x_{i}}^{x_{i+1}} \exp \left(\int_{x_{0}}^{x} \frac{\Lambda_{x y} \frac{\partial T}{\partial y}+\Lambda_{x z} \frac{\partial T}{\partial z}-V_{x} T}{T \Lambda_{x x}} \mathrm{~d} x\right) \mathrm{d} x} ; \quad(18) \\
\left(I_{x}\right)_{i+\frac{1}{2} j k}=\frac{T_{i+1 j k} \exp \left(\int_{x_{i}}^{x_{i+1}} \frac{\Lambda_{x y} \frac{\partial T}{\partial y}+\Lambda_{x z} \frac{\partial T}{\partial z}-V_{x} T}{T \Lambda_{x x}} \mathrm{~d} x\right)-T_{i j k}}{\frac{1}{\Lambda_{x x}} \int_{x_{i}}^{x_{i+1}} \exp \left(\int_{x_{i}}^{x} \frac{\Lambda_{x y} \frac{\partial T}{\partial y}+\Lambda_{x z} \frac{\partial T}{\partial z}-V_{x} T}{T \Lambda_{x x}} \mathrm{~d} x\right) \mathrm{d} x} ;
\end{gathered}
$$$$
\int_{x_{i}}^{x_{i+1}} \frac{\Lambda_{x y} \frac{\partial T}{\partial y}+\Lambda_{x z} \frac{\partial T}{\partial z}-V_{x} T}{T \Lambda_{x x}} \mathrm{~d} x=
$$$$
=\int_{x_{i}}^{x_{i+1}} \frac{\Lambda_{x y} \frac{T_{i j+1 k}-T_{i j k}}{h_{y}}+\Lambda_{x z} \frac{T_{i j k+1}-T_{i j k}}{h_{z}}-V_{x} T_{i+\frac{1}{2} j k}}{T_{i+1 j k} \Lambda_{x x}} \mathrm{~d} x=
$$$$
=\frac{\Lambda_{x y} \frac{T_{i j+1 k}-T_{i j k}}{h_{y}}+\Lambda_{x z} \frac{T_{i j k+1}-T_{i j k}}{h_{z}}-V_{x} T_{i+\frac{1}{2} j k}}{T_{i+1 j k} \Lambda_{x x}}\left(x_{i+1}-x_{i}\right) ;
$$

$\int_{x_{i}}^{x_{i+1}} \exp \left(\int_{x_{i}}^{x} \frac{\Lambda_{x y} \frac{\partial T}{\partial y}+\Lambda_{x z} \frac{\partial T}{\partial z}-V_{x} T}{T \Lambda_{x x}} \mathrm{~d} x\right) \mathrm{d} x \approx$

$\approx \int_{x_{i}}^{x_{i+1}} \exp \left(\frac{\Lambda_{x y} \frac{T_{i j+1 k}-T_{i j k}}{h_{y}}+\Lambda_{x z} \frac{T_{i j k+1}-T_{i j k}}{h_{z}}-V_{x} T_{i+\frac{1}{2} j k}}{T_{i+1 j k} \Lambda_{x x}}\left(x_{i}-x\right) \mathrm{d} x=\right.$

$=\frac{T_{i+1 j k} \Lambda_{x x}}{\Lambda_{x y} \frac{T_{i j+1 k}-T_{i j k}}{h_{y}}+\Lambda_{x z} \frac{T_{i j k+1}-T_{i j k}}{h_{z}}-V_{x} T_{i+\frac{1}{2} j k}}$.

$$
\begin{aligned}
& \left(I_{x}\right)_{i+\frac{1}{2} j k}=\Lambda_{x x}\left(\begin{array}{l}
\left.\exp \left(\frac{\Lambda_{x y} \frac{T_{i j+1 k}-T_{i j k}}{h_{y}}+\Lambda_{x z} \frac{T_{i j k+1}-T_{i j k}}{h_{z}}-V_{x} T_{i+\frac{1}{2} j k}}{T_{i+1 j k} \Lambda_{x x}} \cdot\right) \cdot x_{i+1}-x_{i}\right) \\
\cdot T_{i+1 j k}-T_{i j k}
\end{array}\right) / \\
& \int \frac{1}{\frac{\Lambda_{x y} \frac{T_{i j+1 k}-T_{i j k}}{h_{y}}+\Lambda_{x z} \frac{T_{i k+1}-T_{i j k}}{h_{z}}-V_{x} T_{i+\frac{1}{2} j k}}{T_{i+1 j k} \Lambda_{x x}}\left(x_{i+1}-x_{i}\right)} . \\
& \cdot\left(\exp \left(\frac{\Lambda_{x y} \frac{T_{i j+1 k}-T_{i j k}}{h_{y}}+\Lambda_{x z} \frac{T_{i j k+1}-T_{i j k}}{h_{z}}-V_{x} T_{i+\frac{1}{2} j k}}{T_{i+1 j k} \Lambda_{x x}}\left(x_{i+1}-x_{i}\right) h_{x}\right)-1\right) \text {. }
\end{aligned}
$$

$\Lambda$ definīcija ir šãda:

$$
\begin{aligned}
& \Lambda_{x x}=\frac{\lambda_{x x}}{n \rho c}, \Lambda_{x y}=\frac{\lambda_{x y}}{n \rho c}, \Lambda_{x z}=\frac{\lambda_{x z}}{n \rho c} ; \\
& \Lambda_{y x}=\frac{\lambda_{y x}}{n \rho c}, \Lambda_{y y}=\frac{\lambda_{y y}}{n \rho c}, \Lambda_{y z}=\frac{\lambda_{y z}}{n \rho c} ; \\
& \Lambda_{z x}=\frac{\lambda_{z x}}{n \rho c}, \Lambda_{z y}=\frac{\lambda_{z y}}{n \rho c}, \Lambda_{z z}=\frac{\lambda_{z z}}{n \rho c} ; \\
& \lambda_{x x}=n \rho c\left(\beta_{T} V+\left(\beta_{c}-\beta_{T}\right) \frac{\mathrm{v}_{x} \mathrm{v}_{x}}{V_{x x}}\right) ; \\
& \lambda_{x y}=n \rho c\left(\beta_{T} V+\left(\beta_{c}-\beta_{T}\right) \frac{\mathrm{v}_{x} \mathrm{v}_{y}}{V_{x y}}\right) ; \\
& \lambda_{x z}=n \rho c\left(\beta_{T} V+\left(\beta_{c}-\beta_{T}\right) \frac{\mathrm{v}_{x} \mathrm{v}_{z}}{V_{x z}}\right) ; \\
& \lambda_{y x}=n \rho c\left(\beta_{T} V+\left(\beta_{c}-\beta_{T}\right) \frac{\mathrm{v}_{y} \mathrm{v}_{x}}{V_{y x}}\right) ; \\
& \lambda_{y y}=n \rho c\left(\beta_{T} V+\left(\beta_{c}-\beta_{T}\right) \frac{\mathrm{v}_{y} \mathrm{v}_{y}}{V_{y y}}\right) ; \\
& \lambda_{y z}=n \rho c\left(\beta_{T} V+\left(\beta_{c}-\beta_{T}\right) \frac{\mathrm{v}_{y} \mathrm{v}_{z}}{V_{y z}}\right) ; \\
& \lambda_{z x}=n \rho c\left(\beta_{T} V+\left(\beta_{c}-\beta_{T}\right) \frac{\mathrm{v}_{z} \mathrm{v}_{x}}{V_{z x}}\right) ; \\
& \left.\lambda_{z z}\right) \\
& V_{z z}\left(\beta_{T} V+\left(\beta_{c}-\beta_{T}\right) \frac{\mathrm{v}_{z} \mathrm{v}_{z}}{V_{z z}}\right)
\end{aligned}
$$


kur $n$-materiāla porozitātes koeficients; $\rho$ - ùdens blīvums; $c$ - ùdens siltuma jauda (tiek pienemts, ka siltuma avots ir izvietots $\bar{u}$ den̄i, jo tiek pien,emts, ka ķīmiskās reakcijas ūden̄̄ veido temperatūras pieaugumu [3]); $\beta_{c}, \beta_{T}$-garenvirziena un šķērsvirziena termiskā dispersija [1], [4]; $V$ - ātruma modulis formulā ieejošo asu virzienos; $v_{x}, v_{y}, v_{z}-\bar{a}$ truma komponentes asu virzienos.

Lai veidotu paralēlos aprēkinus, veicot izveidotās diferenču shēmas aprēķinus, tiek veikta diferenču shēmas dekompozīcija pa distanci un laiku, lietojot ADI (Alternating Direction Implicit) pamatprincipus. Rezultātā diferenču shēma siltuma izplatīšanās aprēķiniem no laika momenta $l$ līdz laika momentam $l+1$ tiek pārveidota un sadalīta trijos etapos:

$$
\begin{aligned}
& \frac{T_{i j k}^{l+\frac{1}{3}}-T_{i j k}^{l}}{\frac{\tau}{3}}=\frac{Q T_{i j k}}{n R_{T}}+\frac{1}{R_{T}} \frac{\partial}{\partial x}\left(\left(\begin{array}{c}
l+\frac{1}{3} \\
I_{x}
\end{array}\right)_{i+\frac{1}{2} j k}-\left(\begin{array}{c}
l+\frac{1}{3} \\
I_{x}
\end{array}\right)_{i-\frac{1}{2} j k}\right)_{x=x^{*}, y=y^{*}, z=z^{*}}+ \\
& +\frac{1}{R_{T}} \frac{\partial}{\partial y}\left(\left(\begin{array}{c}
l \\
I_{y}
\end{array}\right)_{i j+\frac{1}{2} k}-\left(\begin{array}{c}
l \\
I_{y}
\end{array}\right)_{i j-\frac{1}{2} k}\right)_{x=x^{*}, y=y^{*}, z=z^{*}}+ \\
& +\frac{1}{R_{T}} \frac{\partial}{\partial z}\left(\left(\begin{array}{c}
l \\
I_{z}
\end{array}\right)_{i j k+\frac{1}{2}}-\left(\begin{array}{c}
l \\
I_{z}
\end{array}\right)_{i j k-\frac{1}{2}}\right)_{x=x^{*}, y=y^{*}, z=z^{*}} ;
\end{aligned}
$$

$$
\begin{aligned}
& \frac{T_{i j k}-T_{i j k}}{\frac{\tau}{3}}=\frac{Q T_{i j k}}{n R_{T}}+\frac{1}{R_{T}} \frac{\partial}{\partial x}\left(\left(\begin{array}{c}
l+\frac{1}{3} \\
I_{x}
\end{array}\right)_{i+\frac{1}{2} j k}-\left(\begin{array}{c}
l+\frac{1}{3} \\
I_{x}
\end{array}\right)_{i-\frac{1}{2} j k}\right)_{x=x^{*}, y=y^{*}, z=z^{*}}+ \\
& +\frac{1}{R_{T}} \frac{\partial}{\partial y}\left(\left(\begin{array}{c}
l+\frac{2}{3} \\
I_{y}
\end{array}\right)_{i j+\frac{1}{2} k}-\left(\begin{array}{c}
l+\frac{2}{3} \\
I_{y}
\end{array}\right)_{i j-\frac{1}{2} k}\right)_{x=x^{*}, y=y^{*}, z=z^{*}}+ \\
& +\frac{1}{R_{T}} \frac{\partial}{\partial z}\left(\left(\begin{array}{c}
l+\frac{1}{3} \\
I_{z}
\end{array}\right)_{i j k+\frac{1}{2}}-\left(\begin{array}{c}
l+\frac{1}{3} \\
I_{z}
\end{array}\right)_{i j k-\frac{1}{2}}\right)_{x=x^{*}, y=y^{*}, z=z^{*}}
\end{aligned}
$$

$$
\begin{aligned}
& \frac{T_{i j k}^{l+\frac{3}{3}}-T_{i j k}^{l+\frac{2}{3}}}{\frac{\tau}{3}}=\frac{Q T_{i j k}}{n R_{T}}+\frac{1}{R_{T}} \frac{\partial}{\partial x}\left(\left(\begin{array}{c}
l+\frac{2}{3} \\
I_{x}
\end{array}\right)_{i+\frac{1}{2} j k}-\left(\begin{array}{c}
l+\frac{2}{3} \\
I_{x}
\end{array}\right)_{i-\frac{1}{2} j k}\right)_{x=x^{*}, y=y^{*}, z=z^{*}}+ \\
& +\frac{1}{R_{T}} \frac{\partial}{\partial y}\left(\left(\begin{array}{c}
l+\frac{2}{3} \\
I_{y}
\end{array}\right)_{i j+\frac{1}{2} k}-\left(\begin{array}{c}
l+\frac{2}{3} \\
I_{y}
\end{array}\right)_{i j-\frac{1}{2} k}\right)_{x=x^{*}, y=y^{*}, z=z^{*}}+ \\
& +\frac{1}{R_{T}} \frac{\partial}{\partial z}\left(\left(\begin{array}{c}
l+\frac{3}{3} \\
I_{z}
\end{array}\right)_{i j k+\frac{1}{2}}-\left(\begin{array}{c}
l+\frac{3}{3} \\
I_{z}
\end{array}\right)_{i j k-\frac{1}{2}}\right)_{x=x^{*}, y=y^{*}, z=z^{*}} .
\end{aligned}
$$

Formulās (35)-(37) tāpat kā formulā (3) atvasinājumu vērtības tiek rēkinātas punktos $x^{*}=\left(x_{i}-x_{i-1}\right) / 2, y^{*}=\left(y_{j}-y_{j-1}\right) / 2$, $z^{*}=\left(z_{k}-z_{k-1}\right) / 2$.

$A D I$ tehnologijas lietojums ḷauj veikt aprēkininus ātrāk un ḷauj veidot aizklāto diferenču shēmu piecu punktu šablonam divu koordinātu virzienos tā, lai tiktu izveidota vienādojumu sistēma ar trīs diagonāḷu matricu, kuras atrisināšanai ir iespējams izmantot Tomasa algoritmu. Līdz ar to aprēķini tiek paātrināti.

Lai padarītu aprēḳinu procesu vēl ātrāku, tiek aprēḳināti iterāciju laika soḷi atkarībā no prognozētiem siltuma izplatīšanās aprēḳiniem nākamajā iterācijā. Šādai pieejai ir vairāki soḷi:

1) aprēķināt absolūto un relatīvo kḷūdu starp prognozējamo siltuma izplatîšanās rezultātu un aprēkininu rezultātu;

2) atrast maksimālo kḷūdas vērtību;

3) izrēḳināt nākamās iterācijas laika soli pēc algoritma, kas parādīts 1. attēlā;

4) veikt siltuma izplatīšanās prognozi nākamajai iterācijai.

$\operatorname{If}\left[\left(\right.\right.$ ErrorXYZ $\left.\geq \frac{\text { toltol }}{2}\right), \tau 1=\tau ; \tau=\frac{\tau}{\tau \text { koef }} ; \operatorname{If}[\tau<\tau$ min,$\tau=\tau$ min $\left.] ;\right] ;$
$\operatorname{If}\left[\left(\right.\right.$ ErrorXYZ $\left.\leq \frac{\text { toltol }}{2}\right) \bigwedge\left(\right.$ ErrorXYZ $\left.\left.\geq \frac{\text { toltol }}{5}\right), \tau 1=\tau ; \tau=\tau\right] ;$
$\operatorname{If}\left[\left(\right.\right.$ ErrorXYZ $\left.\leq \frac{\text { toltol }}{5}\right), \tau 1=\tau ; \tau=\tau$ * kkoef; If $\left.[\tau>\tau \max , \tau=\tau \max ] ;\right] ;$

1. att. Nākamās iterācijas laika soḷa aprēḳina algoritms. ErrorXYZ maksimālā kḷūda starp prognozējamo siltuma izplatīšanās rezultātu un aprēḳinu rezultātu, toltol - uzdots kḷūdas līmenis, $\tau$ - laika solis, $\tau k o e f$ - laika soḷa izmaiņas koeficients, $\tau$ min - minimālais laika solis, $\tau$ max - maksimālais laika solis.

Papildus izmantojamais uzlabojums algoritmam ir diferenču shēmas normalizācija pēc attāluma un laika.

Attāluma normalizācija sākas ar apskatāmā 3D apgabala maksimālā izmēra pa koordinātu asīm noteikšanu. Pēc tam visi izmantojamie attāluma soḷi un 3D punktu pozīcijas tiek dalītas ar iegūto vērtību. Laika normalizācija tiek lietota laika solim, to dalot ar apskatāmā 3D apgabala maksimālā izmēra vērtību, kāpinātu kvadrātā.

\section{REZULTĀTI}

Izveidotā diferenču shēma ir aizklāta, bet tās aprēḳinu procesa ātrums ir kontrolējams un paātrināms. Aprēḳinu rezultātu piemērs parādīts 2 . attēlā. 


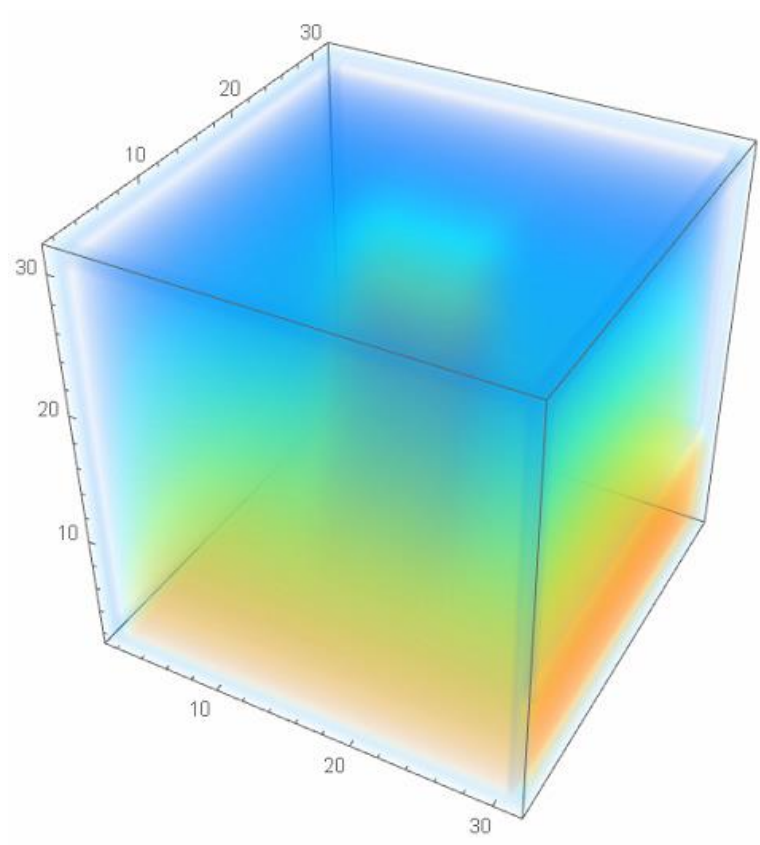

2. att. Aprēḳina piemērs. Krāsu skala parāda temperatūru celsija grādos analizējamajā apgabalā. Analizējamā apgabala centrālajā daḷā ir siltuma avoti.

2. attēlā parādītie rezultāti no cita skatu punkta ir redzami 3. attēlā.

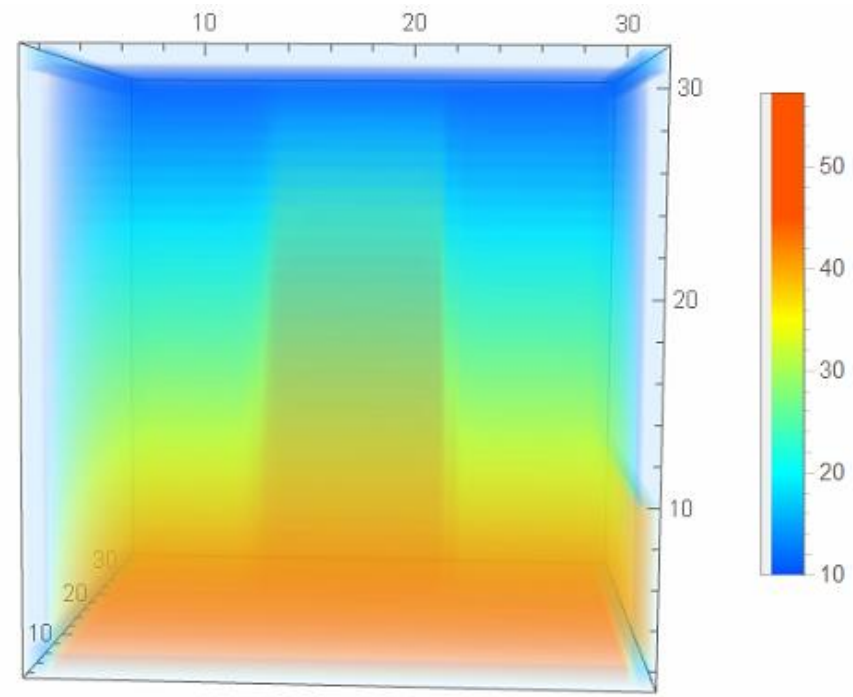

3. att. Izveidotā risinājuma aprēḳinu procesa rezultāts.

3. attēla vertikālā griezuma $2 \mathrm{D}$ bilde bez caurspīdīgām zonām tiek paradīta 4 . attēlā.

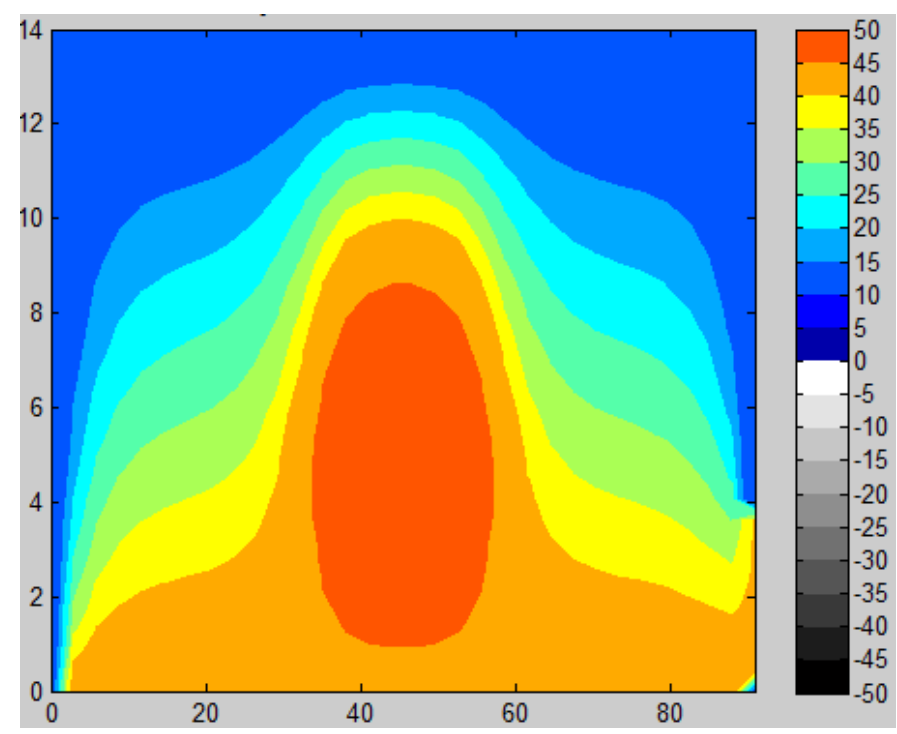

4. att. Aprēḳinu rezultāta vertikāls griezums.

\section{SECINĀJUMI}

Izstrādāta monotona, konservatīva eksponenciālā diferenču shēma temperatūras izplatīšanās aprēḳiniem, lietojot $A D I$ pamatprincipus. Ievērojamākais uzlabojums izveidotai diferenču shēmai ir samazinātais aprēḳinu laiks, kas tiek sasniegts, izmantojot algoritma blokus, kas nav savstarpēji saistīti. Tas nozīmē, ka pastāv iespēja veikt paralēli š̄ algoritma fragmentu aprēķinus. Tas ir ievērojams uzlabojums 3D aprēķiniem.

Izstrādātais risinājums l̦auj izmantot dinamisko laika soli aprēķinu procesā.

\section{LITERATŪRAS SARAKSTS}

[1] R. Sethi and A. D. Molfettav, "Heat Transport Modeling in an Aquifer Downgradient a Municipal Solid Waste Landfill in Italy," American Journal of Environmental Sciences, vol. 3, issue 3, pp. 106-110, 2007. https://doi.org/10.3844/ajessp.2007.106.110

[2] H. Yoshida, N. Tanaka, and H. Hozumi, "Theoretical Study on Heat Transport Phenomena in a Sanitary Landfill," in Proc. of Sixth International Landfill Symposium (SARDINIA'97), 13-17 October, 1997, pp. 109-120.

[3] C. Zheng and P. Wang, "MT3DMS: A Modular Three-Dimensional Multispecies Transport Model for Simulation of Advection, Dispersion and Chemical Reactions of Contaminants in Groundwater Systems," Contract Report SERDP-99-1, 1999.

[4] M. C. Zanetti, L. Manna, and G. Genon, "Biogas production evaluation by means of thermal balances," in 6th International Landfill Symposium Sardinia 97, 13-17 October 1997, pp. 523-531. 


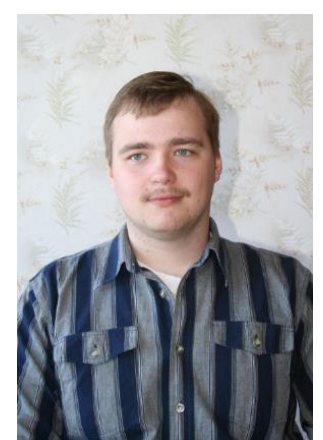

Maksims Žigunovs received $\mathrm{Mg}$. sc. ing. in Information Technologies in 2013. He defended his Master thesis at Liepaja University, Latvia. Since 2016, he has been a Ph.D. student with Riga Technical University. Major areas of his scientific activity are heat transfer implementations, environment process modelling and parallel calculation technologies applied and theoretical usage in software usage/creations.

E-mail: maksims.zigunovs@inbox.1v

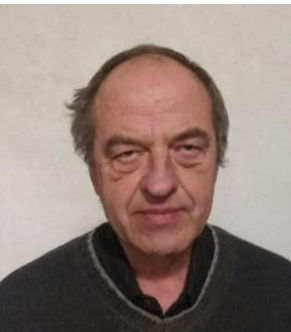

Ilmārs Iltiňs is a Professor with the Department of Engineering Mathematics of Riga Technical University. Major areas of his scientific activity are inverse problems of heat conduction, stability analysis of flows, numerical methods.

E-mail: ilmars.iltins@rtu.lv

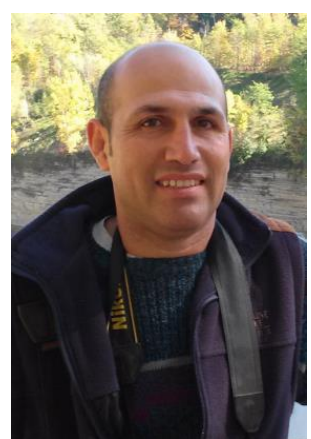

Michael A. Radin Ph.D., is an Associate Professor of Mathematics, with the Rochester Institute of Technology, Rochester, New York, U.S.A.

His research areas are difference equations, discrete neural networks, modeling human emotions and pedagogy.

He spent sabbatical in Latvia in spring 2016 and has been a lecturer at Liepaja University and Riga Technical University.

E-mail: michael.radin@rit.edu

The Solution of the Heat Conduction Equation in 3D Anisotropic Environment and Possibilities of its Improvement

Maksims Žigunovs ${ }^{1}$, Ilmārs Iltiņš2 $\check{2}^{\text {Michael A. Radin }}{ }^{3}$

${ }^{1,2}$ Riga Technical University, Latvia, ${ }^{3}$ Rochester Institute of Technology, U.S.A

Nowadays there are high speed improvements in processors frequencies and processors amount on a single map. So these opportunities have to be used in such fields as modeling and simulation, prediction models and simulations. One of these fields is strictly connected with the article's subject (heat conduction). Heat conduction calculation in 3D space is quite a problem for 3D space calculations because the time spent on calculation for usual approaches is quite long. It is possible to separate full iteration of heat conduction calculation into several portions. These portions of calculation could contain separate calculation blocks. It is possible to implement using ADI (Alternating Direction Implicit) principles in dividing full iteration of heat conduction calculation into 3 parts. Each of these parts ignores one of the directions of coordinate axes, but allows to calculate only three diagonal matrix using Thomas algorithm. It means that additional effort on difference scheme construction has the payback of calculation time reducing because of separated calculable blocks. Another boost of calculation speed is dynamic time step implementation by taking into account the prediction matrix of next iteration heat transfer calculations. This approach has no strict impact on time step calculations for each next iteration, but it can be bordered between the possible minimal and maximal time step defined values. Provided solutions allow to manage algorithm calculation time by applying as many computers as many times as needed to reduce the calculation time.

Keywords - heat conduction, improvement, high performance computing. 